\title{
Inhibitory STDP improves temporal processing in disynaptic circuits
}

\author{
Florence I Kleberg ${ }^{1 *}$, Matthieu Gilson², Tomoki Fukai ${ }^{1}$ \\ From Twenty Second Annual Computational Neuroscience Meeting: CNS*2013 \\ Paris, France. 13-18 July 2013
}

Spike trains with temporal correlations have been related to cognitive and sensory processing [1], and extraction of correlation information may therefore be of great importance to neuronal computations. Synaptic plasticity rules such as Spike-Timing Dependent Plasticity (STDP) allow selective increases of synaptic weights that receive correlated spike input, allowing the neuron to detect correlation in its input [2,3]. Though this has been shown in excitatory synapses, only few studies have addressed the functional properties of STDP in inhibitory synapses $[4,5]$.

It is known that excitatory and inhibitory activities are typically balanced [6], and maintenance of a 'detailed balance' within signaling pathways has been shown to achieve useful gating properties [7]. Therefore, combining plasticity mechanisms in excitatory and inhibitory weights in the same model could provide insight in how such a balance can arise, and what possible functions inhibitory synaptic plasticity can fulfill in the presence of input spike trains with varying statistics.

In this study, we use a Leaky-Integrate-And-Fire neuron with inputs that model a canonical disynaptic feedforward-inhibitory circuit (Figure 1). We show analytically and computationally that this detailed balance can be achieved by STDP in inhibitory and excitatory synapses, depending on the characteristics of the inhibitory STDP learning window. Our results further indicate that in such a configuration, the postsynaptic response to excitatory inputs is rendered more reliable in time, and that there is an optimal inhibitory delay for which this improvement is effective. Moreover, we extend our model to explicitly simulate the fast-spiking inhibitory neurons, and confirm that inhibitory neurons are recruited to different sources of correlation by STDP,

\footnotetext{
* Correspondence: kleberg@brain.riken.jp

'RIKEN BSI, Wakoshi, Saitama, 351-0109, Japan

Full list of author information is available at the end of the article
}

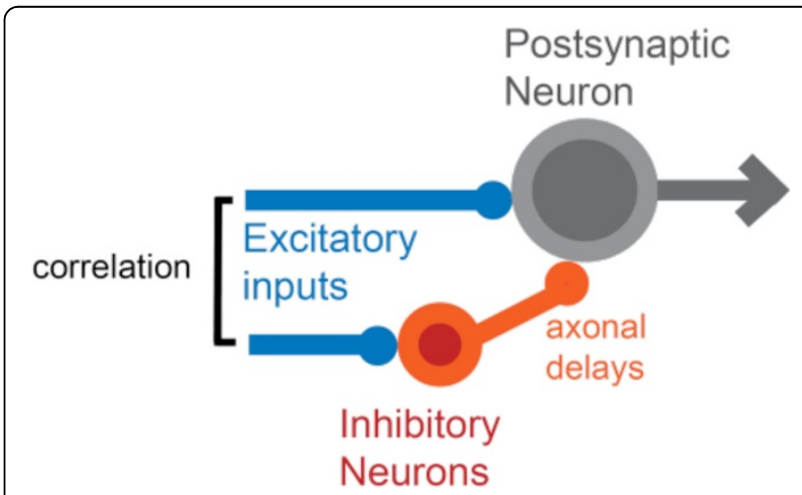

Figure $1 \mathrm{~A}$ canonical disynaptic feed-forward circuit considered in our study. The inhibitory input is modeled as a delayed spike train, correlated with the excitatory input.

and that inhibitory synapses subsequently follow the same scenario as in the single-neuron model.

Our findings provide insight in the role of inhibitory STDP, in maintaining detailed balance and enhancing transmission efficacy in disynaptic neural circuits.

\section{Author details}

'RIKEN BSI, Wakoshi, Saitama, 351-0109, Japan. Universitat Pompeu Fabra, Barcelona, E-08018, Spain.

Published: 8 July 2013

References

1. Riehle A, Gruen S, Diesmann M, Aertsen A: Spike Synchronization and rate modulation differentially involved in motor cortical function. Science 1997, 278:1950-1953.

2. Song S, Abbott LF: Cortical development and remapping through spiketiming dependent plasticity. Neuron 2001, 32:339-350.

3. Gilson M, Fukai T: Stability versus neuronal specialization for STDP: Longtail weight distributions solve the dilemma. Plos One 2011, 6(10):e25339.

4. Vogels TP, Sprekeler H, Zenke F, Clopath C, Gerstner W: Inhibitory Plasticity balances excitation and inhibition in sensory pathways and memory networks. Science 2011, 334:1569-1573.

5. Luz Y, Shamir M: Balancing feed-forward excitation and inhibition via Hebbian inhibitory synaptic plasticity. Plos Comp Biol 2012, 8:e1002334. 
6. Shu Y, Hasenstaub A, McCormick DA: Turning on and off recurrent balanced cortical activity. Nature 2003, 423:288-293.

7. Vogels TP, Abbott LF: Gating multiple signals through detailed balance of excitation and inhibition in spiking networks. Nat Neurosci 2009, 12:483-491.

doi:10.1186/1471-2202-14-S1-P134

Cite this article as: Kleberg et al:: Inhibitory STDP improves temporal processing in disynaptic circuits. BMC Neuroscience 2013 14(Suppl 1):P134.

Submit your next manuscript to BioMed Central and take full advantage of:

- Convenient online submission

- Thorough peer review

- No space constraints or color figure charges

- Immediate publication on acceptance

- Inclusion in PubMed, CAS, Scopus and Google Scholar

- Research which is freely available for redistribution

Submit your manuscript at www.biomedcentral.com/submit
C Biomed Central 